\title{
Development of Virtual Reality Game-Based interfaces for Civil Engineering Education
}

\author{
Fábio Matoseiro Dinis, Ana Sofia Guimarães, Bárbara Rangel Carvalho, João Pedro Poças Martins \\ Dept. of Civil Engineering \\ Faculty of Engineering of the University of Porto, FEUP \\ Porto, Portugal
}

\begin{abstract}
Virtual Reality (VR) is gradually becoming a part of the life of the average person as hardware prices become more affordable for the end user. A growing variety of hardware allows users to engage in a series of immersive experiences for ludic, educational or even professional activities. In this regard, the diversity of affordable solutions could provide an alternative to highly immersive, but expensive environments such as, CAVE experiences [1]. The development of VR technologies is starting to spread its influence to the AECO (Architecture, Engineering, Construction and Operations) sector through the creation of new work methodologies and techniques, as well as original interfaces for communication. Creating new tools for the discussion of topics and providing collaborative work among participants with different backgrounds provides opportunities not only for the industry, but also for applications in education. The development of VR applications and its outcomes, regarding the acceptance (or lack of it) from the students will be the focus of this paper. The description of three case studies will be fully detailed, providing data analysis from each one of the tests conducted.
\end{abstract}

Keywords-interaction; Virtual Reality; Game-Based Learning; Information Technology; Engineering Education

\section{INTRODUCTION}

In many countries, in particular in those where the recent financial and economic crisis was felt more acutely, Higher Education Institutions (HEI) are now faced with the difficult task of motivating students into pursuing careers in fields where professional short-term prospects were severely affected.

Considering 2008 as the beginning of the financial crisis, Fig. 1 shows the variation in the number of employees in Civil Engineering in some of the southern countries of the EU [2]. Ireland is also represented in Fig. 1 since it has requested external financial support similarly to Portugal and Greece.

The numbers suggest a future shortage of Civil Engineering skills, and has thus prompted HEIs to consider the adoption of new methodologies and teaching approaches to engage future professionals.

Believable correlation between Architecture, Engineering, Construction and Operations sector (AECO) professional opportunities and economic prospects and the number of candidates to Civil Engineering courses might be established.

To access HEIs, after completing their secondary courses in the Portuguese system, students need to apply for a spot in a specific institution. Students are ranked according to their grades in admission tests and fill the available vacancies. The applications are available during three different phases.

According to the Portuguese Directorate-General for the Higher Education (DGES - Direcção-Geral do Ensino Superior), the total number of available positions in Civil Engineering courses at public HEIs were 525 (first phase 2015/2016) while only 119 candidates selected Civil Engineering as their primary option [3].

The number of candidates who selected Civil Engineering as their first option at Faculdade de Engenharia da Universidade do Porto (FEUP) (2016/2017), was significantly lower than the 130 available vacancies. Indeed, at the end of three application stages, only 96 students enrolled into the Civil Engineering course. A relevant aspect that should not be unnoticed is that among these 96, now first year students, merely 17 chose Civil Engineering as their first option (2 at the first phase, 10 at the second and 5 students at the third phase of applications) [4 and 5].

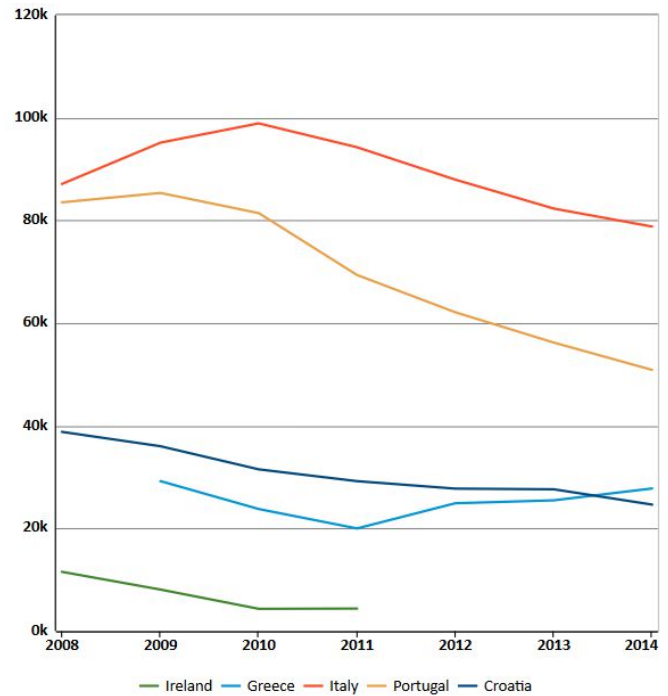

Fig. 1. Number of employees in Civil engineering in some countries particularly affected by the financial and economic crises.

In the last few years, Virtual Reality (VR) has shown multiple potential solutions which are gradually attaining their own space in people's lives. The massification of VR technologies is largely driven by the entertainment industry, driving hardware prices that are increasingly affordable to the average person [1]. In general, VR applications are currently supported without the need for professional-grade hardware. 
Therefore, the implementation of VR technologies becomes easier and gradually more affordable not only for the end user, but also for industrial and educational related applications. The latter, is part of the scope of this work, which regards the application of VR interfaces for Engineering Education, specifically for Civil Engineering contexts.

VR technology, for its capacity of immersion and innovation aspects, is assumed as a suitable technology to be explored for its educational and pedagogic applications.

The Educational Laboratory - Big Machine (ELBigMAC) project, co-funded by the Erasmus+ program, aims to develop an "educational laboratory" which should be deployed in different environments. The laboratory will be replicated and adapted to match different climate conditions and needs, local construction techniques and building solutions.

ELBigMAC's objectives are not only to show students how to build different solutions on site, but also to present innovative technologies like VR applied to Civil Engineering contexts. Students will learn to design and interact with building systems using virtual tools and equipment like Head Mounted Displays (HMD) and dedicated software.

In sum, ELBigMAC aims to develop pedagogical methodologies and general teaching know-how in a collaborative and sharing learning environment.

The second section of this paper demonstrates the evolution of VR related concepts and equipment.

Three different case studies were carried out during this study and are presented in this paper. The details concerning the equipment used to develop the VR platforms are described in section three of this work. The hardware tested during the case studies supports the development of natural user interfaces (NUI), allowing user interaction to be as natural and effortless as possible.

The VR interfaces developed were tested in three distinct moments.by a variety of participants. These tests are described concerning the ability to improve the transferability of knowledge, and the usability of such interfaces. Students from different schools had the opportunity to learn and test the platforms, stepping into virtual environment trials each one representing a different Civil Engineering scenario.

Every participant in the trials or case studies was surveyed at the end of the practical experiences. To assess the validity of the developed platform, the users were asked to evaluate various aspects related to the adequacy and usability of the interface. The potential of the platform to be used as a means for enhancing the perception of information was also assessed. The results of the inquiries were analysed and are reported in the fourth section of this paper.

\section{VR EQUIPMENT DEVELOPMENT AND APPLICATIONS - A BRIEF CONTEXTUALIZATION}

\section{A. Overview of VR equipment major developments in the $X X$ century}

Virtual Environments (VE) features and capabilities had already been explored years before the most recent flourishing interest in VR technologies. In 1965, Sutherland writes about the "Ultimate Display" describing: "a room within which the computer can control the existence of matter" [6]. In terms of immersive environments, the CAVE was initially presented at SIGGRAPH 92' as one of the four distinctive directions of Virtual Reality research at that time (Cathode Ray Tube (CRT), HMD, Binocular Omni-Oriented Monitor and CAVE). The CAVE distinguished itself from alternative solutions for being, among other aspects, a collaborative visualization tool, with enhanced field of view and high resolution interface [7]. In fact, CAVEs are still used today in research facilities and HEIs.

HMDs are also one of the directions VR may be explored. "The Sword of Damocles", created by Sutherland in the 60's, was one of the first created. A heavy machinery suspended from the laboratory ceiling attached to a mechanical arm., able to track the user's movements and display information accordingly [8].

Currently the offer of HMDs available in the market increases every year. HMDs can reach higher costs if they are meant for computationally demanding applications. However, some solutions exploiting mobile devices' processing capabilities are available at affordable prices and have their own suitable applications as well.

\section{B. Application of VR technologies through various fields of knowledge}

VR technology has long since moved beyond its more popular uses prescribed by the entertainment industry. Indeed, many practises have been given to this technology in different domains.

Fernández-Palacios, Morabito, and Remondino [9] explored the use of VR immersive proprieties in the field of Archaeology. Through an HMD users could visit real inaccessible sites and explore valuable archaeological spaces supported by graphical information.

The application of VR to architecture, landscape architecture and environmental planning was explored in [10] as a means of reaching physically inaccessible realities, evaluate users' behaviour based on changes in the virtual model, of supporting decision-making, improving user's experience and feedback.

Kunz, Zank, Fjeld and Nescher [11] developed a solution for factory planning involving immersive and "walkable" experiences using VR equipment. This work describes a solution that allows users to physically walk in a real room and have their movements detected and replicated within a virtual space.

The advantages of using virtual mock-ups instead of real models to experience unique aspects of design and functionality of hospital patient rooms are described in [12]. 
The immersion aspect of VR and the potential of Immersive Virtual Environments (IVEs) are demonstrated in [13]. The authors state the added value of IVEs to obtain end users' input and participation in the design discussion of projects.

The benefits of VR technologies in construction engineering education are explored in [14]. This research involved immersive VR experiments related to construction schedules, planning and methodologies. The authors suggest that the use of VR immersive displays can improve and help revolutionize educational techniques in engineering.

Deshpande and Huang [15] discusses the need for virtual integration and game simulation based applications for a holistic understanding and support of the transferability of academic knowledge between students.

The application of game platforms particularly designed for educational purposes can also be used to study scenarios where data-collecting is very limited. Uwe, and Schatz [16] developed a serious game, "Serious Human Rescue Game", to explore human behaviour in extreme situations, e.g. during the evacuation process of a burning building. Through this game, different situations can be explored and assessed, for example, an earthquake and its intrinsic structural damage, an explosion, smoke proliferation, etc.

\section{VR INTERFACES DEVELOPMENT}

\section{A. Building Models using a VR interface - First VR Case Study}

The main objectives of this work entail the assessment of VR game-based platforms designed to introduce the field of Civil Engineering to pre-university students.

During the ELBigMAC project, students will learn how VR interfaces can be applied to Civil Engineering environments, acting as tools to quickly interact with virtual building models and edit geometry and proprieties for different results.

The interaction with VR interfaces was developed to be as natural as possible to overcome expected challenges such as the students' lack of experience with complex building modelling applications. Indeed, many pre-university students had never used building design software or other professional Civil Engineering and Architecture programs. Thus, a versatile and user friendly solution was developed to ease the learning curve of the interface. The association of VR with a Natural User Interface (NUI) environment enables the users to engage in a fast-paced learning process, using skills and motions that are very familiar to them from other scenarios and activities [17].

The VR interfaces presented in this paper were developed using one of the most popular 3D game engines, Unity 3D. The software allows the creation of virtual environments based on many tools and assets and it accepts data input from different sources, including building design software.

The first VR interface developed was based on the work produced during a Master's Thesis in Civil Engineering [18], concerning the development and application of a platform for the interaction between BIM (Building Information Modelling) and VR.
Eastman, Teicholz, Sacks and Liston define BIM as “...a modelling technology and associated set of processes to produce, communicate, and analyse building models." [19]. BIM can also be defined as a collaborative methodology designed to manage, connect, plan and support all the processes and activities related to a building life-cycle.

There are many different interfaces that already allow users to visualize BIM models through mobile devices. The interface developed in this work, besides the visualization aspect, adds the capacity of editing models directly from the IVE. The BIM model, which was initially imported to the game engine, is updated automatically every time the user edits the model through VR inputs. These inputs can be produced through a regular game controller or using a motion detection sensor [20].

The building model was developed using a commercial BIM modelling software, Autodesk Revit 2016. The model was then exported as a Filmbox file (FBX), and imported into the game engine, Unity 3D. A set of routines were developed and added to the virtual environment as scripts. These routines include essential movement controllers as well as controls that enable the user to manipulate individual game objects [20]

An HMD was used to allow the user to navigate the surrounding environment, responding to physical head movements. The commands that complemented the movement through the scene (player's translation - front, back, left and right) were operated through the gamepad's left analogue button.

The interaction with the game objects can be performed using two alternative input interfaces: the gamepad and the Leap Motion gestural detection sensor (Fig.2). These interfaces allow the user to select, move, rotate and copy individual objects.

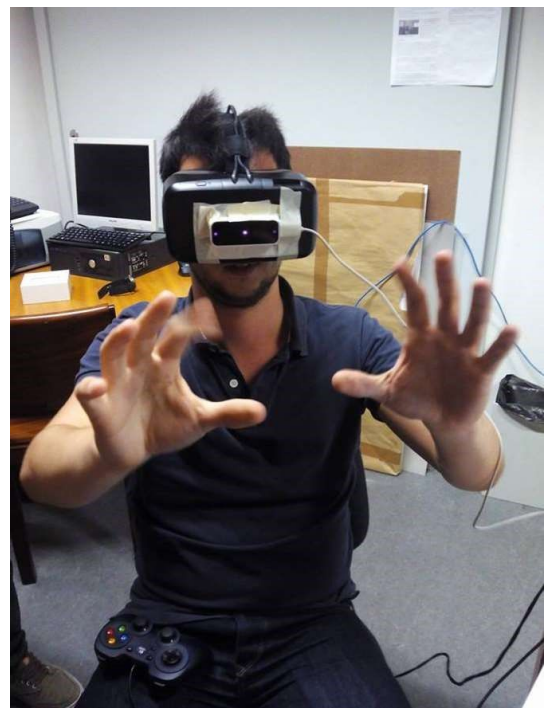

Fig. 2. Example of one type of interface made available to the participants gestural commands

\section{1) Description of the first Case Study}


Participants explored a virtual model of a building, and simultaneously tested a variety of specific controls designed to interact with a $3 \mathrm{D}$ model.

No specific criteria were specified for the selection of participants. The sample $(\mathrm{N}=30)$ was composed by a variety of age categories and academic/professional backgrounds, therefore, emphasizing the inclusive features of the interface being tested.

The NUI allowed users to operate within the virtual environment without the need of previous knowledge in architecture/engineering disciplines or software. The tests occurred individually so that each participant could test the VR platform with no predisposed behaviours.

The trial was conducted in two parts: a tutorial and an assessment stage, both within the VR environment.

In the first part of the trial, users were prompted to test every command with different hardware. A specific part of the virtual model was dedicated to the tutorial, as depicted in Fig.3.

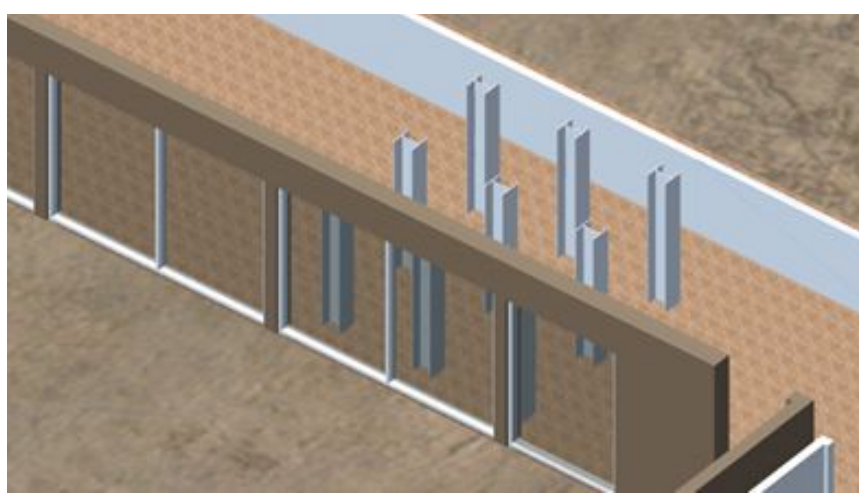

Fig. 3. VR Environment: tutorial zone

The steel columns shown in Fig 3 (see also Dinis [18]) were deliberately placed in the VR scene, so that the participants could understand how the Select, Translation, Rotation and Copy commands performed.

In the second part of the test, users had to fulfil a specific task concerning a copy of a lavatory basin and its correct placement on one of the walls of the compartment. Therefore, the commands learned in the first part of the test should be used to complete the objective.

\section{2) Survey}

After the VR exploration tests were conducted, the users were surveyed to assess the usability and intuitiveness of the commands that were used to interact with the virtual environment. Data was collected on a four point Likert scale and analysed to understand how participants responded to the use of VR as a mean for learning, communicating and perceiving information [18].

\section{B. Exploring a building solution - Second VR Case Study}

A second trial was conducted during a visit of preuniversity students to the faculty campus. In this test, students $(\mathrm{N}=42)$ without previous knowledge about construction systems were invited to participate in a trial where they tested VR equipment (HMD and a regular gamepad) to identify one of the main building systems that can be found in the façades of the campus buildings (Fig.4). In the VR scenario, students also had the opportunity to disassemble the building solution, observe its components and reassemble it on a wall of the virtual model.

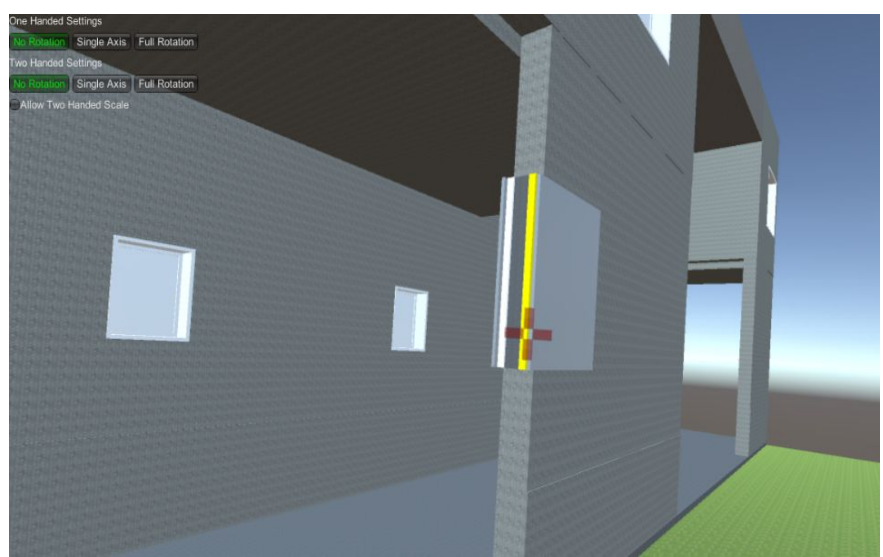

Fig. 4. VR building system presented and explored during the second case study

Through commands design to work with the Leap Motion sensor or the game gamepad, students could identify the different layers that compose the building system.

After the VR trial, all participants were surveyed about their previous knowledge regarding the building system and previous experience with VR equipment. Participants also had to answer questions about the changes after the test concerning the ability to identify examples of the building system around the campus and its corresponding components.

\section{Discovering the main disciplines involved in a Civil Engineering project - Third VR Case Study}

A local school hosted a career fair in November 2016, where pre-university students had the opportunity to establish direct contact with university representatives of the different fields and attend various presentations of HEIs courses. This event played a relevant role explaining to students the scope and opportunities of different job careers they might be interested in the near future.

An exhibition and VR workshop was presented, dedicated to motivate and clarify the scope of intervention of a Civil Engineer.

Firstly, students were encouraged to participate in a preliminary challenge: presenting a few words that might summarize the work of a Civil Engineer. Most students realized that they were mainly associating Civil Engineering with jobsite activities, structure calculations and heavy machinery work. The purpose of this introductory challenge was intended to quickly assess the perception that most students had about the field of Civil Engineering. In fact, none of the 18 students present at the workshop related Civil Engineering to innovation or technological advancements. For this reason, the VR workshop activity took place right after the preliminary challenge. 
In this activity, a virtual environment developed with Unity 3D was revealed to the participants. Through an HMD and using a regular gamepad, volunteers had the opportunity to explore a virtual model of an unidentified school building. This model was exported as an FBX file from the BIM software to the game engine. Thus, a virtual environment was created, enabling users to fully immerge in a VR building model (Fig.5).

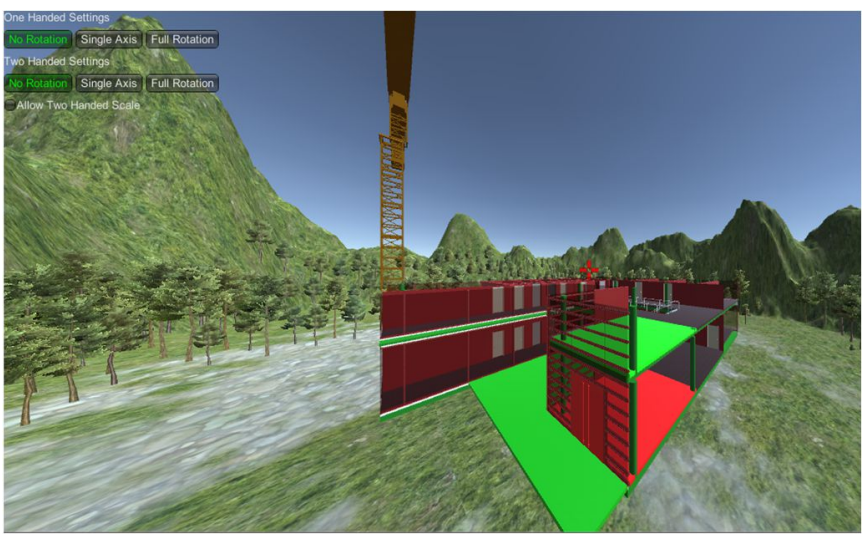

Fig. 5. Virtual model presented to the participants

Another relevant goal of the activity was to explain the main disciplines involved in a Civil Engineering project. Using a gamepad, participants could activate all the objects related to a given discipline of Civil Engineering. Selected objects in the project were displayed in the same colour and thus grouped by discipline: when a button was pressed all the Structural elements altered their original colour to green; after another press the elements concerning the construction discipline had their colour turned red, and lastly, all hydraulics elements would modify their colour to blue if the button was pressed a third time (Fig.6.).

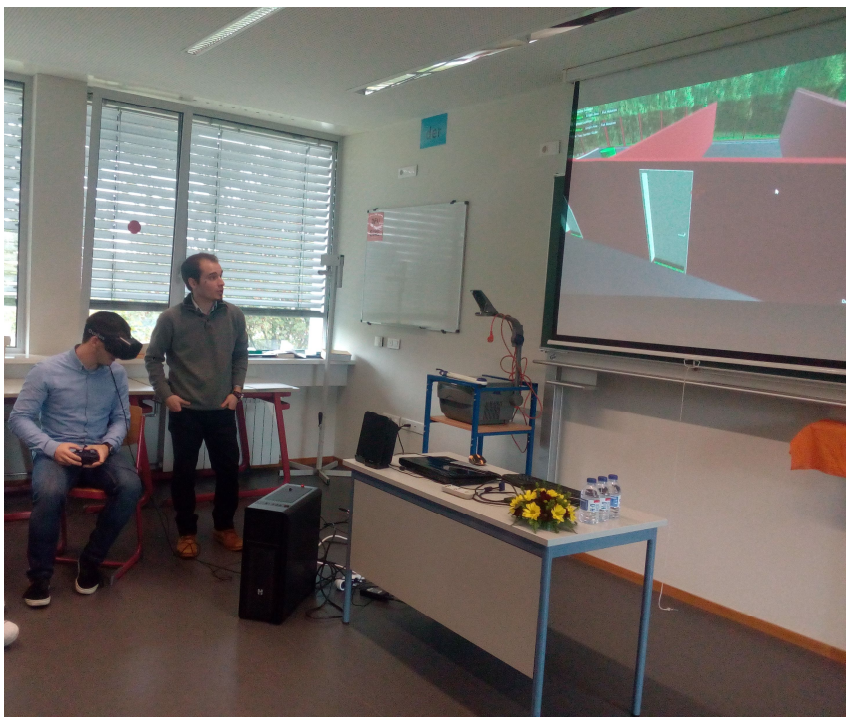

Fig. 6. VR workshop at a local school: using colour codes to identify building systems

The practical trial ended with a brief demonstration about how the Leap Motion sensor could be used to select and move virtual objects. A construction site was also part of the VR scenario and all participants observed how the interface could be used for building a house structure.

In the end of the practical tests and demonstrations, all students were presented with a survey where they were asked about their previous experiences with VR equipment. Furthermore, the validity of the VR experience in terms of providing better conditions to the transferability of information was assessed using a four point Likert scale. Table I shows one of the tables used to assess the potential of the VR test as a tool for enhancing the learning experience.

TABLE I EXAMPLE OF ONE OF THE TABLES OF THE SURVEY USED TO ASSESS THE VR INTERFACE

\begin{tabular}{|c|c|c|c|}
\hline $\begin{array}{c}\text { The VR } \\
\text { interface was } \\
\begin{array}{c}\text { unnecessary to } \\
\text { understand the } \\
\text { concepts }\end{array}\end{array}$ & $\begin{array}{c}\text { The VR } \\
\text { interface was } \\
\text { of little } \\
\text { significance to } \\
\text { understand the } \\
\text { concepts }\end{array}$ & $\begin{array}{c}\text { The VR } \\
\text { interface was } \\
\text { significantly } \\
\text { important to } \\
\text { understand the } \\
\text { concepts }\end{array}$ & $\begin{array}{c}\text { The VR interface was } \\
\text { essential to } \\
\text { understand the } \\
\text { concepts }\end{array}$ \\
\hline & & & \\
\hline
\end{tabular}

\section{DATA ANALYSIS}

\section{A. First VR Case Study}

Given the sample size being embodied of 30 volunteers, the results taken from the data collected through the survey, statistically significant conclusions about the benefits of the VR interfaces cannot be inferred. However, as a preliminary study, the viewpoint of the participants may act as a pointer to the opinion of an end user and such perspective is relevant to the data analysis.

The data collected during the first VR case study was organised in two major groups based on the academic background of the volunteers. Participants related to the AECO sector, (i.e., with previous professional or academic experience) were included in one of the groups. All the volunteers with different study or professional curricula were assigned to another. Furthermore, two subdivisions of these groups were made, separating users without previous experience with VR, especially HMD content, and users who had previous contact with VR before the test. Fig.7. illustrates a schematic of this structure [18].

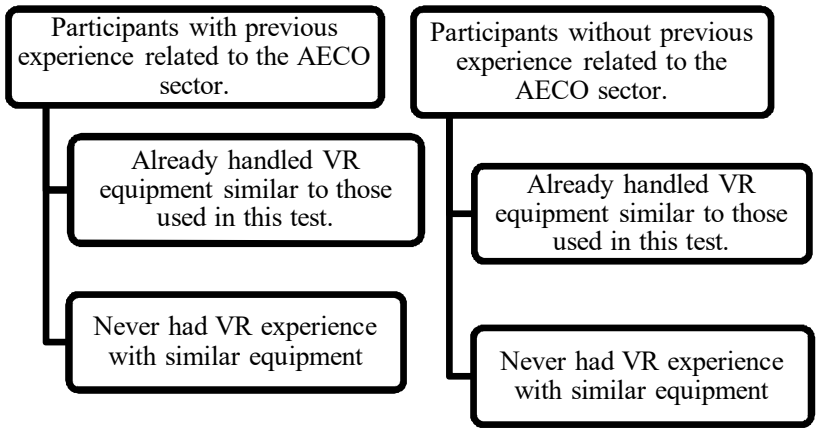

Fig. 7. Selection of groups for data collection 
1) Assessment of the intuitiveness of each of the designed commands to interact with the VR scenario in Unity $3 D$

The surveys conducted after the VR test show that most of the users rated the commands with the two highest classifications of the given scale (four point Likert scale). Indeed, users could interact with the VR interface, in general, with no further or very short previous training.

Fig. 8 and 9 show the results for the 12 participants that had no previous experience in the AECO sector. In the other major group, as illustrated in Fig. 10 and 11, there were 18 participants which had some association, professionally or academically, to the AECO sector.

Fig. 8 and 10 confirm that only 10 participants in this case study had already experienced VR equipment similar to the one used in the test. Users with previous experience in the AECO sector, assessed the interaction, in general, as "requiring a little training". However, most participants with no association with the sector, evaluated the interface, as "Intuitive, does not require previous training".

In general, interactions with the gamepad achieved better results than the gestural commands.

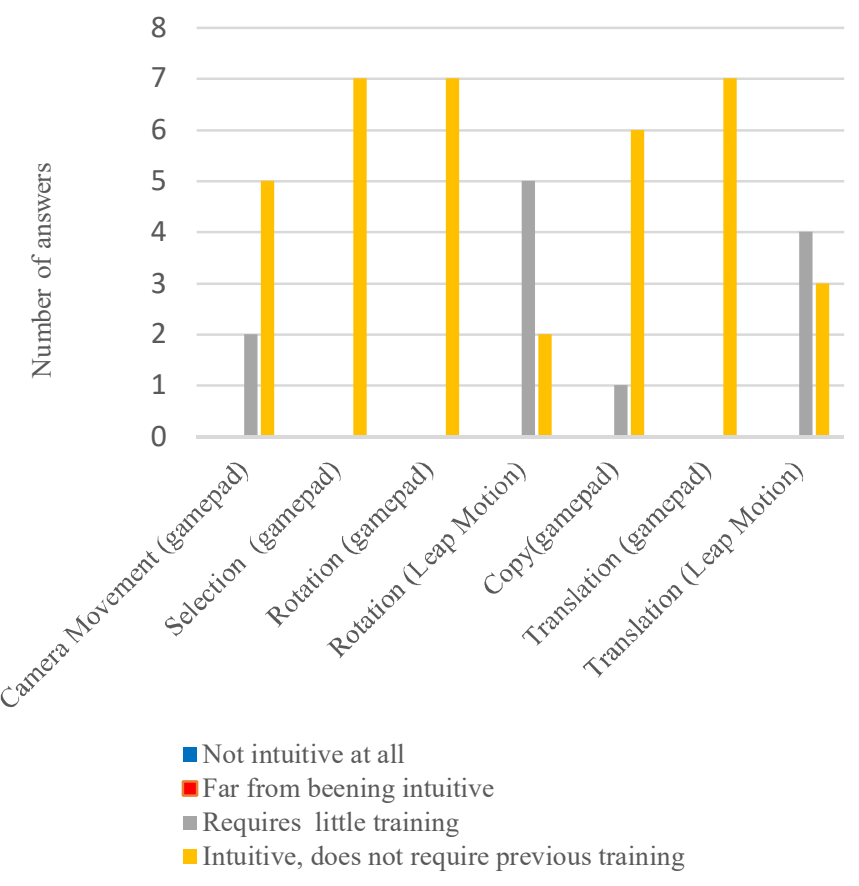

Fig. 8. Participants with no previous knowledge related to the AECO sector and which had handled VR equipment similar to the one used in the case study [18]

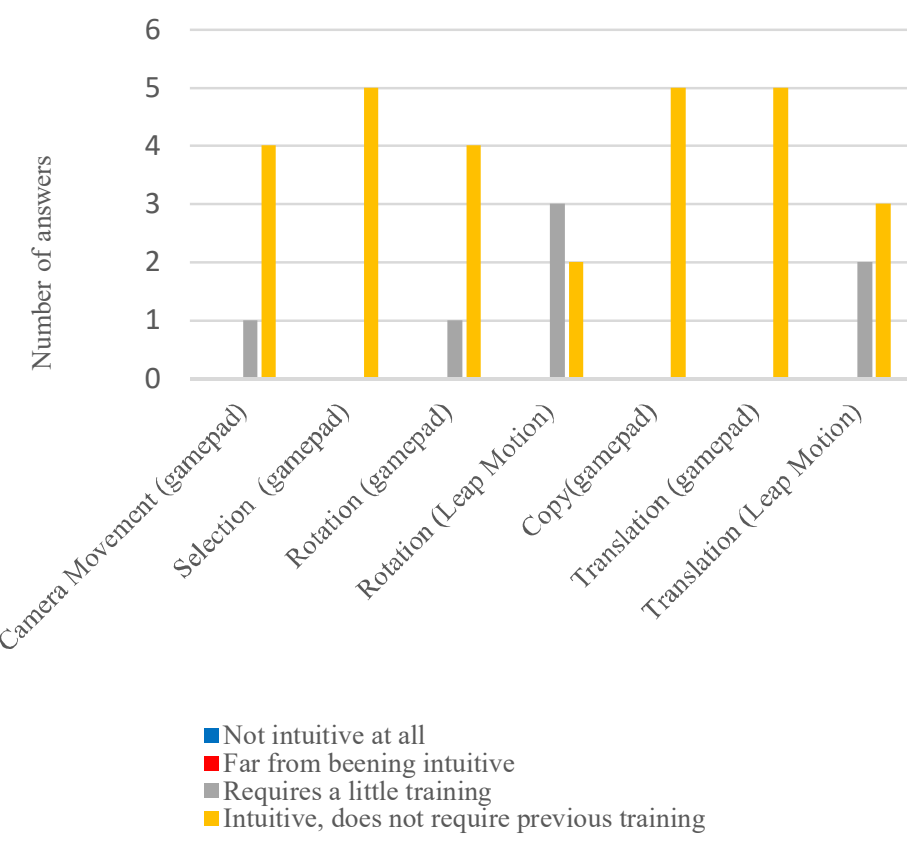

Fig. 9. Participants with_no previous knowledge related to the AECO sector and with no prior VR experience [18]

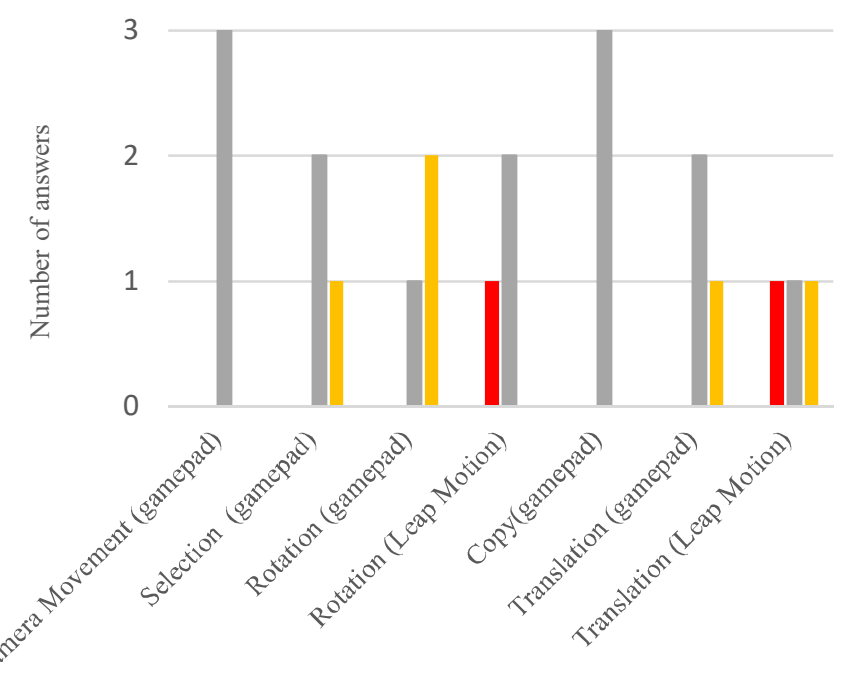

Not intuitive at all

- Far from beening intuitive

Requires a little training

Intuitive, does not require previous training

Fig. 10. Participants with previous knowledge related to the AECO sector and which had handled VR equipment similar to the one used in the case study [18] 


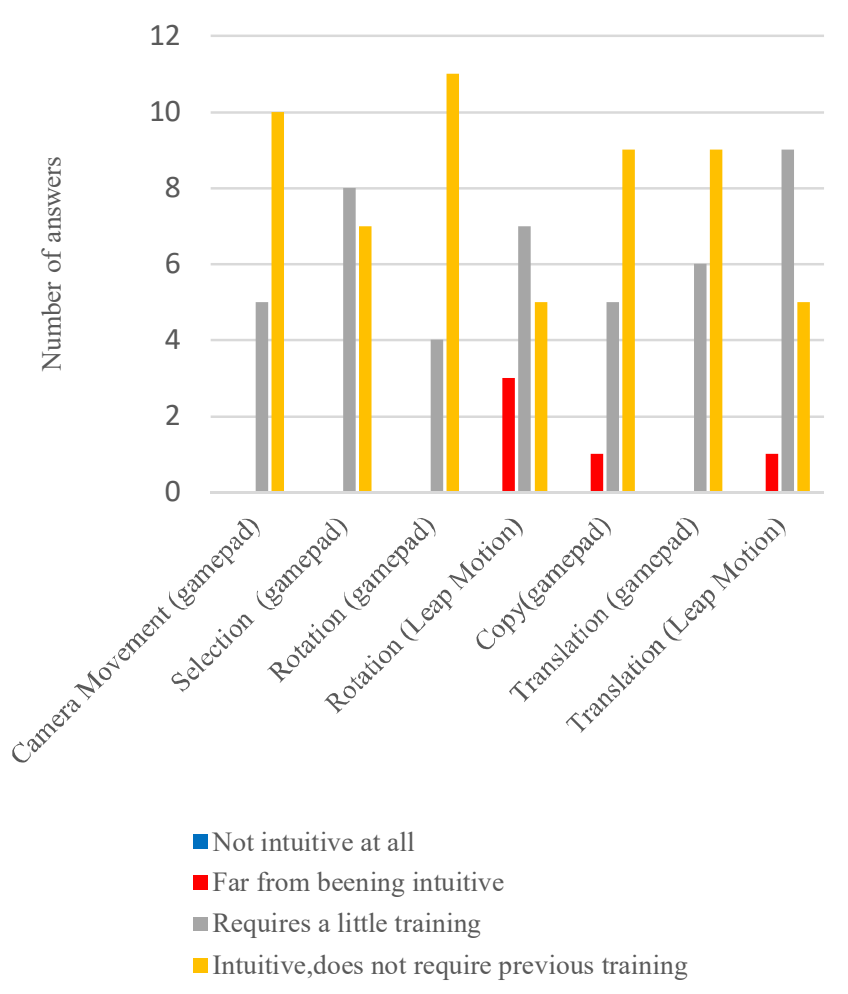

Fig. 11. Participants with previous knowledge related to the AECO sector and with no prior VR experience [18]

\section{B. Second VR Case Study}

The second VR case study was designed to show preuniversity students new practical ways of learning and communicating applied to Civil Engineering Education. Moreover, this test was designed to assess how students would perceive information transmitted through this equipment.

A total of 42 participants were surveyed to assess the viability of the VR solution as a means to present technical information and transfer knowledge. It should be noted that the number of candidates was insufficient to formulate statistically significant conclusions about the behaviour of a broader group of pre-university students. Nevertheless, the results can provide some insight regarding the students' appraisal of VR and what changed after the test.

Table 2 shows that $78.5 \%$ of participants used VR interfaces through an HMD for the first time during the trial.

The majority $(71.4 \%)$ of students did not recognise the ETICS building system beforehand. However, after the test, only $9.5 \%$ of participants confirmed that they were still unable to identify the system and its components, as shown in Table II.
TABLE II DATA COLLECTED FROM THE SURVEY FILLED BY PRE-UNIVERSITY STUDENTS AFTER THE VR TRIAL

\begin{tabular}{|l|c|c|}
\hline \multirow{2}{*}{ Questions presented in the survey } & Yes & No \\
\cline { 2 - 4 } & \multicolumn{2}{|c|}{$\begin{array}{c}\text { Number of } \\
\text { students }\end{array}$} \\
\hline $\begin{array}{l}\text { 1 - Have you tried VR equipment similar to the } \\
\text { Oculus Rift prior to this test? }\end{array}$ & 9 & 33 \\
\hline $\begin{array}{l}\text { 2 - Did you know about ETICS (External } \\
\text { Thermal Insulation Composite Systems) prior to } \\
\text { this test? }\end{array}$ & 12 & 30 \\
\hline $\begin{array}{l}\text { 3 - After the test, do you feel able to identify, in } \\
\text { a simple form, the different components of the } \\
\text { ETICS building system? }\end{array}$ & 38 & 4 \\
\hline
\end{tabular}

\section{Third VR Case Study}

Although 18 participants took part in the trials, only 14 surveys were correctly filled and, therefore, could be considered for further data analysis.

The inquiries showed that most students at this school (71.4\%) had previous knowledge and experience with VR equipment, such as HMDs.

Fig. 12 and 13 show that most of the students answered that VR was a relevant tool to help them understand the concepts being transmitted.

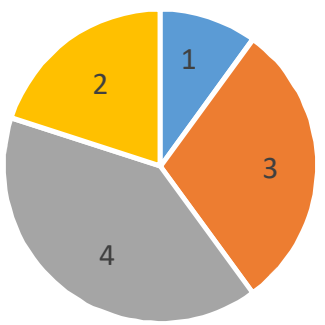

- The VR interface was unnecessary to understand the concepts

- The VR interface was of little significance to understand the concepts

- The VR interface was significantly important to understand the concepts

Fig. 12. Students which had previously handled VR equipment similar to the one used in the case study

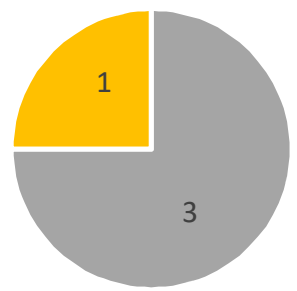

- Unnecessary for better understanding he concepts

- Little significance in terms of enhancing the understanding of the concepts

- Significant improvement in the understanding of the concepts

Fig. 13. Students with no previous experience with VR equipment similar to the one used in the case study 


\section{CONCLUSION}

The VR interfaces developed and tested in this study demonstrated that VR is, in fact, a relevant asset for Civil Engineering Education. Indeed, participants in the first VR case study, from different age groups and academic/professional backgrounds, could interact with the platform, in general, without previous preparation or with little training. Data collected from pre-university students' surveys (second and third case study) show that VR can be used to transfer knowledge between participants, enhancing comprehension of the subjects being presented.

The NUI presented in this work enabled a practical, userfriendly interaction, according to the data collected during the case studies.

As a final note, VR equipment can induce motion sickness in some users. Motion sickness symptoms include the feeling of sudden dizziness and possible nausea, that can be caused by VR equipment, such as HMDs. In the first VR case study a participant felt sick during the practical test. Such situations may become less frequent as new versions of VR equipment, with better screen resolutions and refresh rates, become available.

The work described in this paper will continue to be developed through a recent Erasmus+ program with educational objectives. In the next few years, more complex commands will be integrated in these interfaces, enhancing the immersive features and natural usability of the commands programmed.

\section{ACKNOWLEDGMENTS}

The authors would like to thank the Erasmus + programme for partially supporting this work.

\section{REFERENCES}

[1] Häfner, Polina, Victor Häfner, and Jivka Ovtcharova. 2013. "Teaching Methodology for Virtual Reality Practical Course in Engineering Education." in Procedia Computer Science 25:251-260. doi: http://dx.doi.org/10.1016/j.procs.2013.11.031

[2] "Annual detailed enterprise statistics for construction (NACE Rev. 2, F)." accessed 2016. http://tunisia.opendataforafrica.org/sbs na con r2/annual-detailedenterprise-statistics-for-construction-nace-rev-2-f?regionId=DE.

[3] "Dados e Estatísticas de Cursos Superiores." DGEEC - Direção-Geral de Estatísticas da Educação e Ciência, accessed November 2016.

[4] "Candidatura ao Ensino Superior Público - Colocações 2016." DireçãoGeral do Ensino Superior (DGES)Direção-Geral do Ensino Superior (DGES), accessed November 2016.

[5] Dreção Geral do Ensino Superior Direção de Serviços de Acesso ao Ensino. 2016,. Acesso Superior '16 - Tudo sobre a Candidatura ao Ensino Superior Público. 1st ed, July 2016 ed, Guias do Ensino Superior n. ${ }^{\circ} 108$.

[6] Sutherland, Ivan E. “The Ultimate Display", Proceedings of the IFIP, pp. 506-508 [Proceedings of the IFIP Congress, 1965 ].
[7] Cruzneira, C., D. J. Sandin, T. A. Defanti, R. V. Kenyon, and J. C. Hart. 1992. "The CAVE - Audio-Visual Experience Automatic Virtual Environment" in Communications of the Acm 35 (6):64-72. doi: 10.1145/129888.129892.

[8] Freeman, Daniel. 2008. "Studying and treating schizophrenia using virtual reality: a new paradigm." Schizophrenia bulletin 34 (4):605-610.

[9] Jiménez Fernández-Palacios, Belen, Daniele Morabito, and Fabio Remondino. "Access to complex reality-based 3D models using virtual reality solutions." in Journal of Cultural Heritage. doi: http://dx.doi.org/10.1016/j.culher.2016.09.003.

[10] Portman, M. E., A. Natapov, and D. Fisher-Gewirtzman, "To go where no man has gone before: Virtual reality in architecture, landscape architecture and environmental planning." in Computers, Environment and Urban Systems, 2015, 54:376-384. doi: $\mathrm{http}: / / \mathrm{dx}$.doi.org/10.1016/j.compenvurbsys.2015.05.001.

[11] Kunz, Andreas, Markus Zank, Morten Fjeld, and Thomas Nescher, "Real Walking in Virtual Environments for Factory Planning and Evaluation." in Procedia CIRP, 2015, 44:257-262. doi: http://dx.doi.org/10.1016/j.procir.2016.02.086.

[12] Phillip S. Dunston, Laura L. Arns, James D. Mcglothlin, Gregory C. Lasker,, and and Adam G. Kushner, "An Immersive Virtual Reality Mock-Up for Design Review of Hospital Patient Rooms." In Collaborative Design in Virtual Environments, vol. 48, edited by Xiangyu Wang, (2), Jerry Jen-Hung Tsai and (3), Springer Netherlands, 2011, pp 167-176.

[13] Heydarian, Arsalan, Joao P. Carneiro, David Gerber, Burcin BecerikGerber, Timothy Hayes, and Wendy Wood. "Immersive virtual environments versus physical built environments: A benchmarking study for building design and user-built environment explorations." Automation in Construction, 201,. 54:116-126. doi: http://dx.doi.org/10.1016/j.autcon.2015.03.020.

[14] Messner, John I., Sai C. M. Yerrapathruni, Anthony J. Baratta, and Vaughan E. Whisker. "Using virtual reality to improve construction engineering education." 2003.

[15] Deshpande, Amit A. and Huang Samuel H., "Simulation games in engineering education: A state-of-the-art review." in Computer Applications in Engineering Education, 2011, 19 (3):399--410. doi: 10.1002/cae.20323.

[16] Rüppel, Uwe, and Kristian Schatz,"Designing a BIM-based serious game for fire safety evacuation simulations." in Advanced Engineering $\begin{array}{llll}\text { Informatics, } 2011, & 25 & \text { (4):600-611. }\end{array}$ http://dx.doi.org/10.1016/j.aei.2011.08.001.

[17] Roupé, Mattias, Petra Bosch-Sijtsema, and Mikael Johansson. "Interactive navigation interface for Virtual Reality using the human body." Computers, Environment and Urban Systems, 2014, 43:42-50. doi: .

[18] Dinis, Fábio, "Desenvolvimento de processos de interação entre tecnologia BIM e equipamentos de Realidade Virtual e sua aplicabilidade." master's thesis, Civil Engineering, Universidade do Porto, July 2016.

[19] Eastman, C., P. Teicholz, R. Sacks, and K. Liston, BIM Handbook: A Guide to Building Information Modeling for Owners, Managers, Designers, Engineers and Contractors: Wiley, 2011.

[20] Fábio Dinis, João Poças Martins "Desenvolvimento de interfaces de realidade virtual a partir de BIM e avaliação da sua aplicabilidade." $1^{\circ}$ congresso português de building information modelling, Guimarães, November 2016G. Eason, B. Noble, and I.N. Sneddon, "On certain integrals of Lipschitz-Hankel type involving products of Bessel functions," Phil. Trans. Roy. Soc. London, vol. A247, pp. 529-551, April 1955. 